\title{
CHEAP SENSOR MADE OF MULTICRYSTALLINE SILICON FOR INSOLATION AND TEMPERATURE MEASUREMENTS
}

\author{
TANI CZUJNIK WYKONANY Z KRZEMU KRYSTALICZNEGO \\ DO POMIARÓW NASŁONECZNIENIA I TEMPERATURY
}

\begin{abstract}
In the paper some results on measurement of insolation and „real” cell's temperature carried out with use of standard silicon solar cells are presented. Two identical cells are applied in such a sensor. Short circuit current of one cell is a direct indication of insolation value and open circuit voltage of the other cell is indirect indication of actual sensor's temperature but in this case more complex formula must be used for temperature calculation.
\end{abstract}

Keywords: solar cells, solar sensor, silicon sensor

\section{Introduction}

In the last years in the Europe increase of interest alternative, ecologically pure, energy sources was observed. To this kind of sources belongs sun energy. Photovoltaical conversion is known as the best manner of using sun energy. Exact information about solar radiation is a base to suitable designing of photovoltaic system and to assign possibility of energy gain in relevant insolation and temperature conditions. Generally to measurements of radiation intensity are used two types of detectors:

1. thermocouples and optical thermopiles,

2. semiconductor junction.

Fundamental advantage thermocouple detectors is wide spectrum registered radiation 0.3-2.8 $\mu \mathrm{m}$ and linear dependence answer in function wave-length. They are used in pyranometers and pyrheliometers, as important are measurement of intensity of radiation in maximal wide spectrum of wave-length. They critical defects are high price and long

\footnotetext{
${ }^{1}$ Division of Physicochemical Research, Faculty of Natural Sciences and Technology, University of Opole, ul. kard. B. Kominka 4, 45-032 Opole, Poland, phone +48 7745389 76, email: maria.waclawek@ uni.opole.pl

${ }^{2}$ Chair of Automatics and Biomedical Engineering, Faculty of Electrical Engineering, Automatics, Computer Science and Biomedical Engineering, AGH University of Science and Technology, al. A. Mickiewicza 30, 30-059 Kraków, Poland, phone +48 1261738 31, email: romus@ agh.edu.pl

${ }^{3}$ Institute of Industrial Electrotechnics, Faculty of Electrical Engineering, Czestochowa University of Technology, al. Armii Krajowej 17, 42-200 Częstochowa, Poland, email: zaremba@el.pcz.czest.pl

*Corresponding author: trodziewicz@wp.pl
} 
response time. Response time for detector CM21 made by Kipp\&Zonnen exceed 12 seconds and price is about 2900 euro.

In practice to insolation measurements could be used, with good effect, high quality, special calibrated monocrystalline silicon cells, for which short-circuit current is proportional to intensity of light. Their advantages are low price and fact, that suitable calibrated they can be used to coincident measurements real temperature of coupler [1]. Additionally, if construction of detector is identical as photovoltaic system modules (PV), and are in the same plane - can be assumed that detector shows real average modules temperature, in fact temperature of cells, from which are PV system built. This solution is interesting, because indicates, in compliance with its idea, real temperature of silicon coupler, and not as in case of use temperature-sensitive resistor mounted to rear part of cell (module), temperature of base of cell, which not always correspond to temperature of coupler of investigated cell. Difference of readings in the second case can be in extreme situation even several Celsius degrees. This solution of measurement of insolation and temperature of modules couplers are put into use in automatic photovoltaic system of Opole University and in SolarLab Laboratory in Wroclaw University of Technology.

\section{Influence of adopted semiconductor material on correctness of insolation detectors measurements}

Measurement of solar radiation intensity value with use of semiconductor detector of insolation, is based on measurement value of generated by cell photocurrent, which is comparable with value of short-circuit current of PV cell denoted by mark $I_{S C}$. In that case, value intensity of solar radiation is product of short-circuit current of cell $I_{S C}$ and constant of calibration - $k$ bounded to specific spectral distribution of solar radiation for which calibration was made:

$$
G_{0}=I_{p h} \cdot k \cong I_{S C} \cdot k
$$

On account of, that width of spectral response characteristics of available nowadays semiconductor absorbers are lesser than band of solar radiation, good matching of material used to construction of insolation detectors has important influence on correctness of future measurements. Providing for, that in every photovoltaic cell is generated photocurrent $I_{p h}=A_{a} \cdot \int S R(\lambda) \cdot G_{0}(\lambda) d \lambda$ depend not only on intensity, but as well as on distribution of spectrum, at selection of semiconductor material ought to provide for impact of atmospheric conditions and value of air mass changes on normalized value of cell photocurrent:

$$
\left[I_{p h} / G_{0}\right]_{n o r} \approx\left[I_{s c} / G_{0}\right]_{n o r}
$$

In purpose to display impact of air mass factor value changes (and indirectly changes of spectrum) on relative photocurrent of cells/modules made from different semiconductor materials - function of $f(A M x)$ normalized photocurrent value in expression (3) was defined - to conduct a simulation ach its approximation - expression (4) to make a measurements: 


$$
\begin{gathered}
{\left[\frac{I_{p h}}{G_{0}}\right]_{n o r_{-} A M 1.5}=\frac{\int S R(\lambda) \cdot G_{0}(\lambda) \cdot d \lambda}{\int G_{0}(\lambda) \cdot d \lambda} \cdot \frac{\int G_{0}(\lambda)_{A M 1.5} \cdot d \lambda}{\int S R(\lambda) \cdot G_{0}(\lambda)_{A M 1.5} \cdot d \lambda}} \\
{\left[\frac{I_{p h}}{G_{0}}\right]_{n o r_{-} A M 1.5} \approx\left[\frac{I_{S C}}{G_{0}}\right]_{n o r_{-} A M 1.5}=\frac{I_{S C}}{G_{0}} \cdot \frac{G_{0 A M 1.5}}{I_{S C_{A M 1.5}}}=f(A M x)}
\end{gathered}
$$

where: $G_{0}(\lambda)$ - solar radiation spectrum in time of modules testing; $G_{0}(\lambda)_{\mathrm{AM} 1.5}$ - solar radiation spectrum with distribution type AM1.5 and intensity $G_{0}=1000 \mathrm{~W} / \mathrm{m}^{2}$; $I_{S C}$ - cells/modules short-circuit current at solar radiation intensity $G_{0}$;

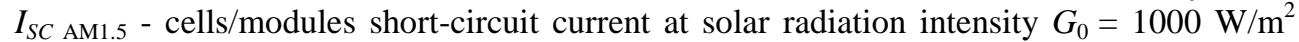
and distribution type AM1.5.

a)

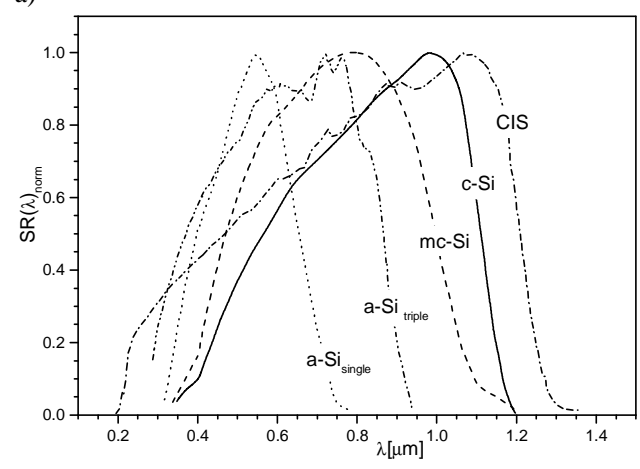

b)

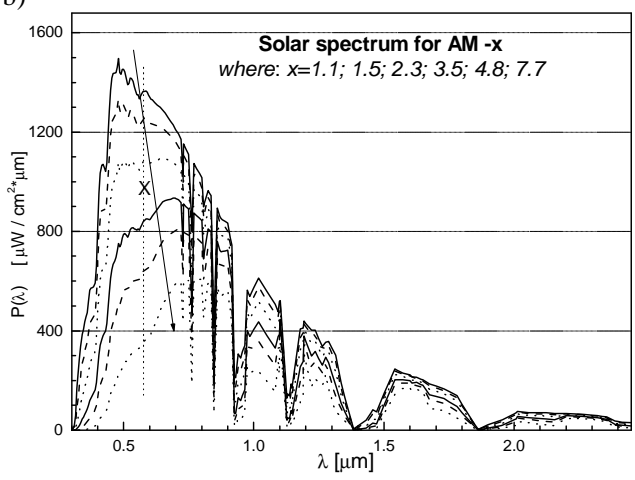

c)

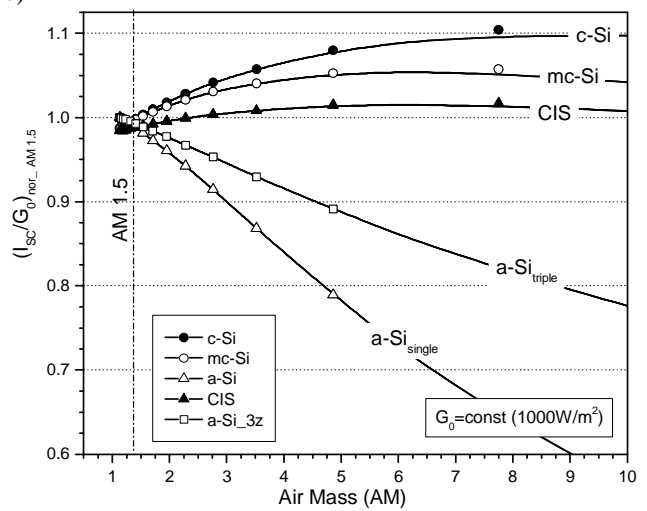

Fig. 1. a) Typical spectral characteristics for modules made by c-Si, mc-Si, a-Si, CIS i triple coupler a-Si; b) Solar spectrum AMx for $\mathrm{x}=1.1 ; 1.5 ; 2.3 ; 3.5 ; 4.8 ; 7.7$; c) Calculated value of normalized photocurrent generated by different modules in function of AM factor value

In Figure 1a results of conducted simulation, showing impact of AM factor (spectrum shape change) on relative cells/modules photocurrent made by different semiconductor materials, were shown. Simulations were made with use of: equation (3) and spectral distribution of solar radiation (clear sky) made for constant values: atmosphere temperature 
$\left(25^{\circ} \mathrm{C} / 298 \mathrm{~K}\right)$, air pressure $(1010 \mathrm{hPa})$, ozone layer thickness $(3 \mathrm{~mm})$ and water vapour thickness $(20 \mathrm{~mm})$ [2-4].

In further theoretical considerations was chosen model of excellent cell (cell in which all photons with suitable energy, that came up on active surface of cell are grabbed by semiconductor, and generate one pair electron-hole). Next these pairs of carriers are divided by internal electric field of " $n-p$ " coupler making so called density photocurrent $\left(J_{p h}\right)$ cell/module, which in short-circuit state is the largest and called the name of short-circuit current density $\left(J_{S C}\right) . I_{S C}$ current value in mainly depends on forbidden band $E_{g}$ as well as on intensity and distribution of solar radiation $G_{0}(\lambda)$, amount of photons $\left(N_{p h}\right)$ in stream of solar radiation with energy higher than semiconductor $E_{g}$, capable of make generation process:

$$
J_{S C}\left(E_{g}\right) \approx J_{p h}\left(E_{g}\right)=q \cdot \int_{E_{g}}^{\infty} N_{p h}\left(E_{g}\right) \cdot d E_{g}
$$

a)

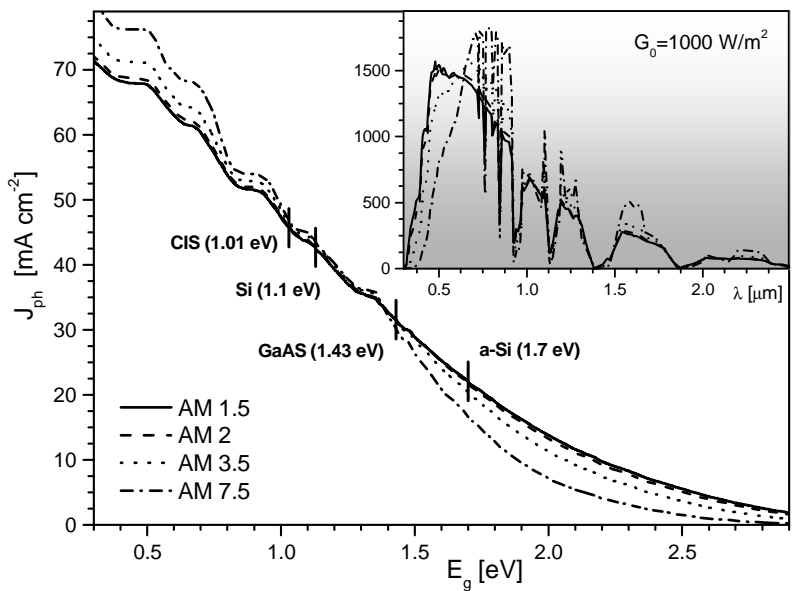

b)

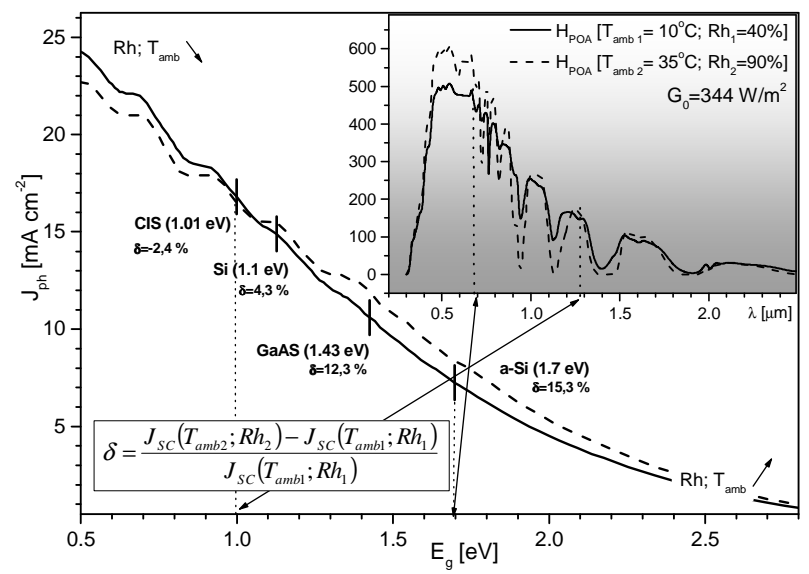

Fig. 2. Maximal photocurrent density in function of semiconductor forbidden band energy $E_{g}$ in condition: a) parametrically changeable air mass value $\mathrm{AM}=1.5 ; 2.0 ; 3.5 ; 7.7$; and $\mathrm{b}$ ) changes $T_{a m b}=10$ and $35^{\circ} \mathrm{C}$, relative humidity $R h=40$ and $90 \%$ 
In Figure 2 was shown impact of atmospheric conditions on generated photocurrent cell/module in function of forbidden band value $E_{g}$ of used semiconductor. It is clear, that for semiconductor PV cell with forbidden band in bracket $E_{g}=(1.1-1.3) \mathrm{eV}$, cells should have the largest stability of parameters by reason of change of air mass factor, temperature and humidity. Detectors of value of solar radiation intensity made from these materials have least measurement error among all another solar radiation detectors made from other semiconductor materials. Above mentioned measurement errors are the effect of solar radiation distribution changes occurred in this location and changeable weather conditions.

\section{Theoretical base for real temperature measurements in p-n coupler of silicon cell}

If construction of photovoltaic detector is similar to construction modules installed in monitored PV system then it can be assumed that real modules temperature in actual weather conditions (insolation, ambient temperature, speed and direction of wind) is equal to detector temperature. Detector of real temperature of $\mathrm{p}-\mathrm{n}$ junction is built from two identical cells (typically they are two halves of one cell), which first one is used to radiation intensity measurement (measurement of $I_{S C}$ ) and second one to measurement of voltage $V_{O C}$. Because value of $V_{O C}$ is function both radiation intensity and temperature, thus through suitable analysis and comparison of findings either measurements it can be find actual value of temperature of $\mathrm{p}$ - $\mathrm{n}$ junction of detector cells.

These type detectors are widely used in Europe to monitoring of photovoltaic system known as „cheap detectors" to measurements value of intensity of solar radiation in PV systems.

Using simple model of one diode replacing schematic of photovoltaic cell

$$
I=-I_{p h}+I_{0} \exp \frac{V-I R_{S}}{A k T}+\frac{V-I R_{S}}{R_{S H}}
$$

and skipping impact of series resistance and leakage and making assumption that $I_{p h}=I_{S C}$, for point $I=0$, can be written, that:

$$
I_{S C}=I_{0} \exp \frac{V_{O C}}{A k T}
$$

where $k$ is Boltzmann constant, $T$ is junction temperature, $I_{S C}$ is value of short-circuit current, $V_{O C}$ is a voltage of open-circuit, $I_{0}$ is a junction saturation current and $A$ is a factor of diode excellence. For same temperature $T_{m}$ and two different values of radiation intensity:

$$
\frac{I_{\text {SCnom }}}{I_{\text {SCm }}}=\frac{\exp \left(V_{\text {OCnom }} / A k T_{m}\right)}{\exp \left(V_{O C m} / A k T_{m}\right)}
$$

where $I_{S C m}$ is measured value of short-circuit current of detector and $I_{S C n o m}$ is value of this current for nominal insolation conditions, for which detector is calibrated. Parameters $V_{O C m}$ and $V_{\text {OCnom }}$ suits respectively values of open circuit voltage of detector for both insolation conditions. Obviously all four parameters involve temperature $T_{m}$, which one is actual temperature of detectors junction. 
After transformation of equation:

$$
V_{\text {OCnom }}-V_{\text {OCm }}=v_{\text {th }} \ln \frac{I_{S C n o m}}{I_{S C m}}
$$

where $v_{t h}=1 / A k T$ is thermal potential of junction and indexes 'nom' and 'm' denotes respectively values measured at nominal radiation intensity (e.g. $1000 \mathrm{~W} / \mathrm{m}^{2}$ ) and values meted in actual conditions.

Because in constant light intensity value of $V_{O C}$ of cell linear depends on temperature, it can be written:

$$
V_{\text {OCnom } \mid T m}=V_{\text {OCSTC }}+\beta\left(T_{m}-T_{S T C}\right)
$$

where $V_{\text {OCnom } \mid T m}$ is value of open circuit voltage of cell for light source intensity corresponded to STC ${ }^{*}$ conditions [5] but for junction temperature $T_{m}, V_{\text {OCSTC }}$ is voltage in light source intensity and junction temperature specified for STC conditions (e.g. AM1.5, $\left.1000 \mathrm{~W} / \mathrm{m}^{2}, 25^{\circ} \mathrm{C}\right), \beta$ is thermal factor of changes of $V_{O C}$ and $T_{S T C}$ is a junction temperature of detector in STC conditions $\left(25^{\circ} \mathrm{C}\right)$.

If value of $V_{\text {OCSTC }}$ is known then actual, real value of detector junction temperature can be computed from equation:

$$
T_{m}=\frac{1}{\beta}\left(V_{O C m}-V_{O C S T C}+v_{t h} \ln \frac{I_{S C n o m}}{I_{S C m}}\right)+T_{S T C}
$$

or, if temperature of junction is known, value of $V_{\text {OCSTC }}$ can be calculated:

$$
V_{O C S T C}=V_{O C m}+v_{t h} \ln \frac{I_{S C n o m}}{I_{S C m}}-\beta\left(T_{m}-T_{S T C}\right)
$$

Equation (11) with experimentally measured relevant constants is added in to calibration certificate of semiconductor detectors.

Foregoing measuring procedure of real junction temperature can be directly transformed to calculating real averaging junction temperature $T_{C}$ in tested photovoltaic module. In case using so called active loading to automatic creation of I-V characteristic tested module, in open-circuit state of module - value of open-circuit voltage $V_{O C}$ of module correspond to voltage of half of cell idle silicon detector. In turn in short-circuit state, current $I_{S C}$ from module correspond to current from so called half of cell working in short circuit state of PV detector. After calibration of module, only on base of its electrical parameter measurements can be calculated value of radiation intensity and averaging temperature of $\mathrm{p}-\mathrm{n}$ junction in tested module.

In Figure 3 open circuit voltage in function of radiation intensity $G_{0}$ and temperature of real photovoltaic module were shown. In purpose increment of readability on figures measurement points weren't draw. Strong correlation between $V_{O C}$ and $T_{C}$ (determination factor $R^{2}=99.1 \%$ ) enable calculating module junction temperature from $V_{O C}$ and $G_{0}[6]$ :

\footnotetext{
* STC (Standard Test Conditions) - normalized conditions of measurement as IEC norm (International Electrotechnical Commission). To compare in believable way parameters of different cells and modules must be tested in so called standard testing conditions (STC). STC necessitate using in measurements: light source with distribution type AM 1.5 and intensity $G_{0}=1000 \mathrm{~W} / \mathrm{m}^{2}$ and module temperature $T=298 \mathrm{~K}\left(25^{\circ} \mathrm{C}\right)$.
} 


$$
T_{C}=25^{\circ}+\frac{V_{O C}-A-B \ln \left(G_{0}-100\right)}{C}
$$

e.g. for $20 \mathrm{~W}$ module made from 36 crystal silicon cells (c-Si) (construction transparent Tedlar, EVA (ethyl vinyl acetate), cells, EVA, $1 \mathrm{~mm}$ Al base - factors are: $A=13.74$; $B=0.94 ; C=-0.074$ at $R^{2}=99.1 \%$.

a)

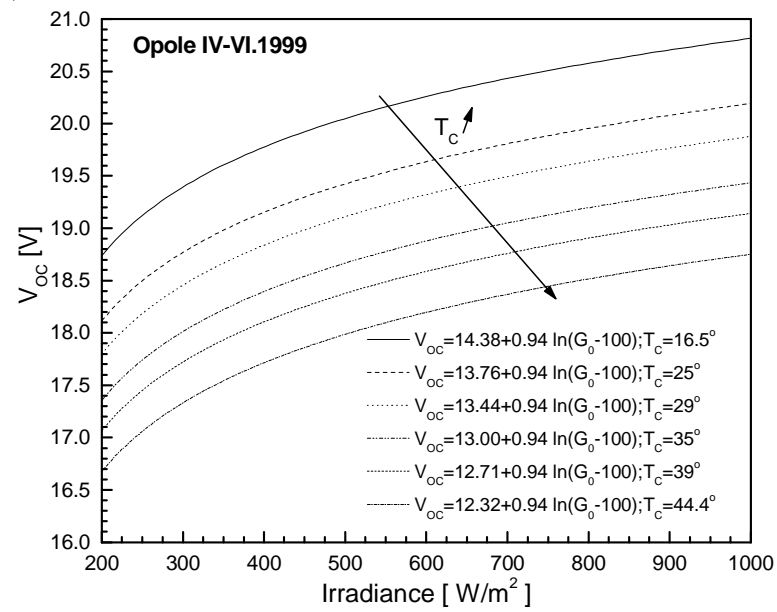

b)

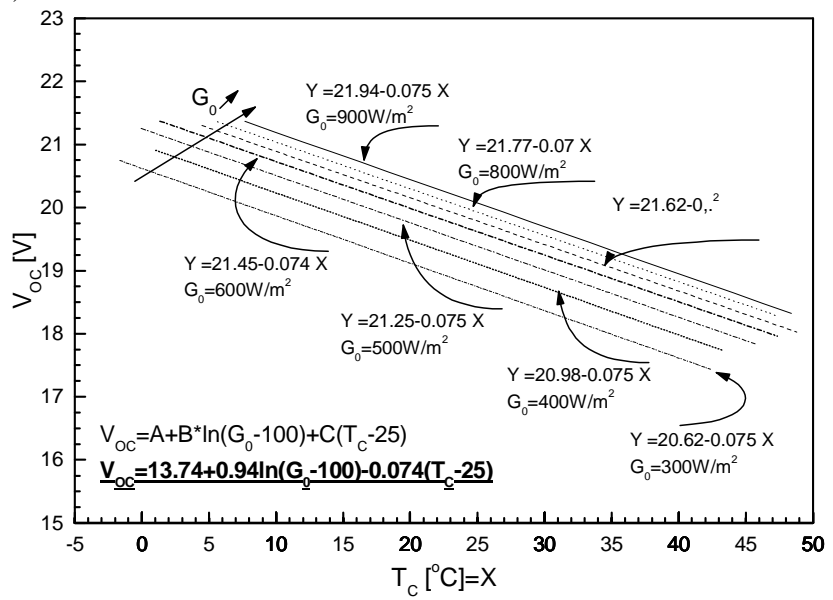

Fig. 3. Impact on open-circuit voltage of PV module of: a) radiation intensity and b) temperature. Findings tested silicon PV module obtained during researches in University of Opole [6]

\section{Silicon detector calibration}

Under investigation were two silicon detectors. Professional detector crafted and calibrated in ESTI and detector made in SolarLab laboratory. Construction differences between these detectors were significant. Ispra detector is covered coarse glass (construction: glass-EVA-cell-EVA-white Tedlar), in turn SolarLab detector is laminated 
thin foil (construction: Tedlar-EVA-cell-EVA-1mm Al base). At the reverse miniature temperature-sensitive resistors type Pt100 were coapted and isolated from direct impact surrounding atmospheric condition. Their indications were supplemented by data respected to ambient temperature $\left(T_{a m b}\right)$. Another constructional difference between investigated detectors is distinct values of $V_{\text {OCSTC }}$ voltage for individual detectors $(576 \mathrm{mV}$ for SolarLab detector and $599 \mathrm{mV}$ for ESTI).

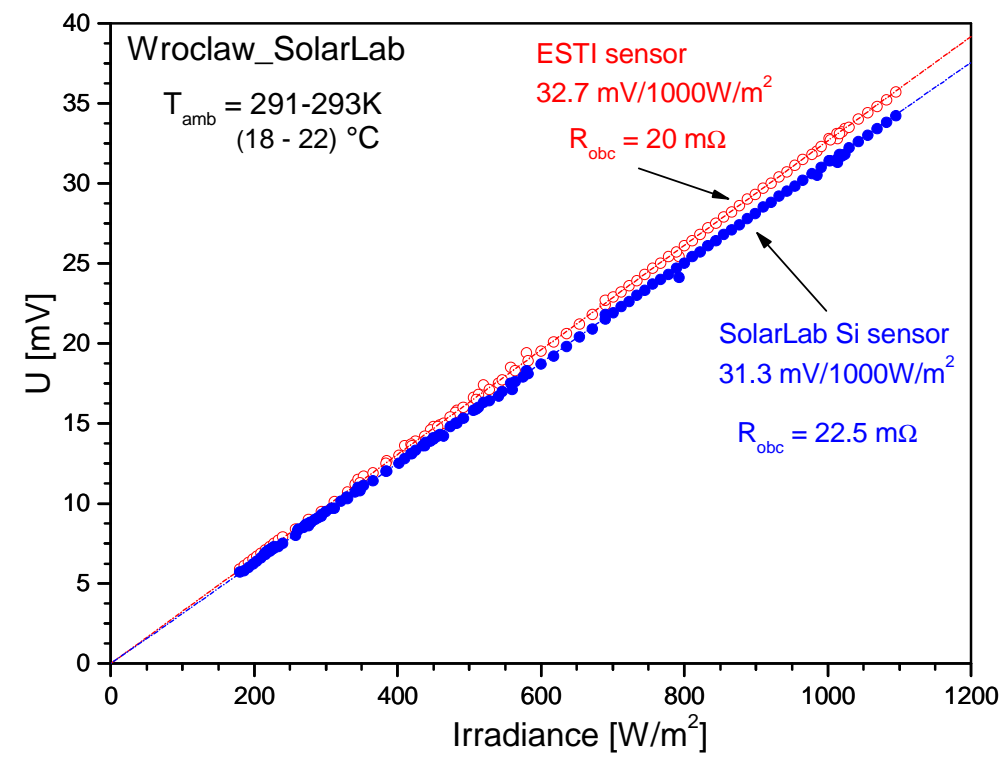

Fig. 4. Calibration of silicon detectors from ESTI and SolarLab with use of global radiation detector type CM11 made by Kipp\&Zonnen [6]

Figure 4 shows effect of calibration for two investigated silicon detectors with use of pyranometer type CM11 Kipp\&Zonnen as a standard. In investigated detectors short-circuit currents were converted on voltage through connection of low resistance loading $(\approx 20 \mathrm{~m} \Omega)$. To calibration filtered data (ambient temperature $T_{a m b} \in(291-293) \mathrm{K}$ ) were used. How can be remarked both detectors shows very good linearity in whole range values of insolation. Figure 5 shows ratio of signals from two tested detectors: ESTI and Solar Lab - found in wide latitude of insolation and ambient temperature changes. On presented figure horizontal line denotes value of calibration for $G=1000 \mathrm{~W} / \mathrm{m}^{2}$ and $T_{a m b}=293 \mathrm{~K}$ and amount to 1.045 (this is a ratio of voltage drops on measurement resistors from investigated cells - $32.7 \mathrm{mV} / 31.8 \mathrm{mV}$ ). For range of lower insolation values and high ambient temperatures ( $T_{a m b}$ measurement was made by temperature-sensitive resistors Pt100) significant difference of indication was observed. This effect is engendered by occurrence of unlike spectral tenderness both detectors, which additionally enlarge rising of ambient temperature. 


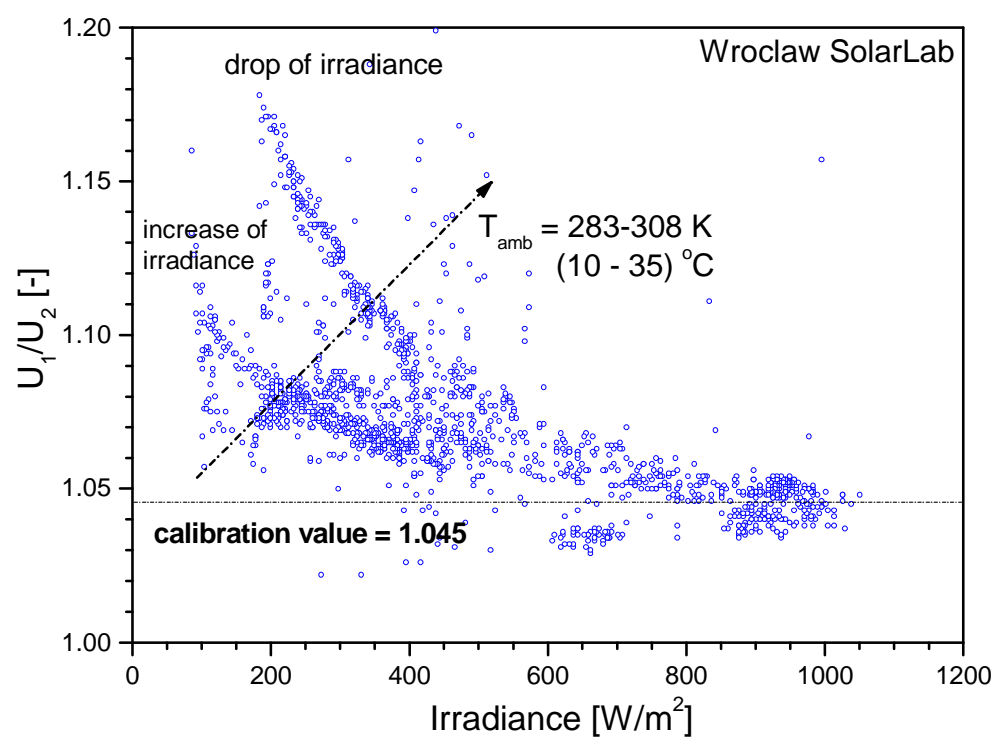

Fig. 5. Ratio of signals from two tested detectors: ESTI and SolarLab - found in wide latitude of insolation and ambient temperature changes [6]

\section{Conclusions}

Basic advantage of silicon cell use as insolation and temperature detector is its low price and relatively acceptable accuracy. Accordingly this solution is encouraging for PV system use. However is ought to remember about two basic use limitations for this type of silicon detectors. First of them is need to use of compound conversion of measured values: $V_{O C}$ and $V_{m}$ to temperature, especially in range low insolation $\left(G_{0}<200 \mathrm{~W} / \mathrm{m}^{2}\right)$. Second is need to apply same construction for detectors and modules, so as to values of thermal inertia of detector and tested modules was comparable. In Figure 4 impact of detector construction on thermal inertia was shown in conditions of changeable ambient temperature - $T_{a m b}$, and insolation - $G$.

\section{References}

[1] Helmke C, Jantsch M, Ossenbrink HA. An assessment of the results of calibrating 600 silicon PV reference devices. Proc. 13th European Photovoltaic Solar Energy Conference and Exhibition, Nice 1995, 2319-2323. DOI: 10.1109/PVSC.1996.564363.

[2] Lorenz D, Backus C. A new technique for predicting silicon solar cell short-circuit currents at reference irradiance conditions. Proc. 15th IEEE Photovoltaic Specialist Conference. Orlando, FL. 1981.

[3] Gueymard C. SMARTS2, Simple Model of the Atmospheric Radiative Transfer of Sunshine: Algorithms and performance assessment, Rep. FSEC-PF-270-95, Florida Solar Energy Center, Cocoa, FL 1995. http://www.fsec.ucf.edu/en/publications/pdf/FSEC-PF-270-95.pdf.

[4] Gueymard C. SMARTS2. http://alpha.fsec.ucf.edu/public/smarts2/ or http://homepage.mac.com/cgueymard.

[5] IEC 60904-3: Measurement principles for terrestrial photovoltaic (PV) solar device with reference spectral irradiance data. 1995. https://webstore.iec.ch/publication/3875.

[6] Żdanowicz T, Rodziewicz T, Ząbkowska-Wacławek M. Zastosowanie ogniw krzemowych w systemach fotowoltaicznych do pomiaru nasłonecznienia i rzeczywistej temperatury modułów (Application of silicon cells in photovoltaic systems to measurements of insolation and real temperature of modules). Chem Inż Ekol. 1998;5(1-2):91-100. 